Soleh, M.A. $\cdot$ R. Manggala $\cdot$ Y. Maxiselly $\cdot$ M. Ariyanti $\cdot$ I.R.D. Anjarsari

\title{
Respons konduktansi stomata beberapa genotipe tebu sebagai parameter toleransi terhadap stress abiotik
}

\section{Stomatal conductance response of sugarcanes under abiotic stress}

\author{
Diterima : 11 Desember 2017/Disetujui : 18 Desember 2017 / Dipublikasikan : 30 Desember 2017 \\ CDepartment of Crop Science, Padjadjaran University
}

\begin{abstract}
The present of global warming coincided by climate change will affect to sugarcane production due to unbalance of distribution of precipitation. Consequently, rainy season is often occurring sporadic and unable to predict. In other hand, water logging in the field has a potential to induce abiotic stress of plants leading effect on yield. One of physiological traits related to abiotic stress is stomatal conductance response $\left(g_{s}\right)$ that represents metabolism of plants such as photosynthesis. Some of sugarcane genotypes grown under the water logging condition shown difference response of $\mathrm{g}_{\mathrm{s}}$ ranged from $240 \mathrm{mmol}$ $\mathrm{s}^{-1}$ of Kidang Kencana (KK) as a local genotypes to $516 \mathrm{mmol} \mathrm{s} \mathrm{s}^{-1}$ of PS921 as a improved genotypes. The difference of $g_{s}$ correlated to canopy temperature where under water logging condition showed higher temperature compared to absent of waterlogging condition. The study is informing $g_{s}$ response of sugarcanes that may useful for breeding program under abiotic stresses of sugarcane in the future.
\end{abstract}

Keywords: stomatal conductance, sugarcane, abiotic stress, waterlogging.

Sari Peningkatan produksi tebu saat ini akan terhambat dengan adanya fenomena pemanasan global yang disertai dengan perubahan iklim hingga mempengaruhi sebaran air hujan. Akibatnya musim hujan sering terjadi secara sporadis dan kurang dapat diprediksi. Di sisi lain kondisi lahan kebanjiran akibat genangan air berpotensi menyebabkan stress abiotik pada

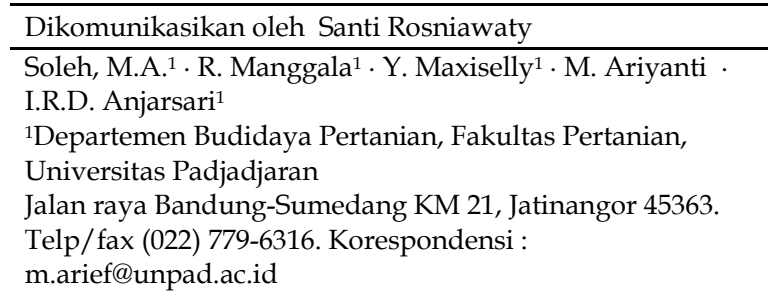

tanaman tebu yang secara langsung berpengaruh terhadap produktivitas tanaman. Salahsatu sifat fisiologis yang berkaitan erat dengan ketahanan stress abiotik adalah respons konduktansi stomata $\left(g_{s}\right)$ sebagai representatif proses metabolisme tanaman berupa fotosintesis. Beberapa varietas tebu ditanam dalam kondisi genangan air memperlihatkan perbedaan nilai $g_{s}$ dari $240 \mathrm{mmol} \mathrm{H}_{2} \mathrm{O} \cdot \mathrm{m}^{-2} \cdot \mathrm{s}^{-1}$ untuk Kidang Kencana $(\mathrm{KK})$ sebagai varietas lokal sampai $516 \mathrm{mmol} \mathrm{H}_{2} \mathrm{O} \cdot \mathrm{m}^{-2} \cdot \mathrm{s}^{-1}$ untuk PS921 sebagai varietas terbarukan. Perbedaan respons $\mathrm{g}_{\text {s }}$ ini selaras dengan peningkatan suhu kanopi tanaman pada perlakuan genangan dibanding tanaman tanpa genangan. Hasil penelitian ini diharapkan mampu memberikan informasi bagi para pemulia tanaman tebu dalam merakit tanaman yang lebih tahan stress abiotik berupa genangan air.

Kata kunci: konduktansi stomata, tebu, cekaman abiotik, genangan.

\section{Pendahuluan}

Peningkatan suhu bumi dalam kurun waktu 10 tahun terakhir mempelihatkan kenaikan yang signifikan dipicu oleh kenaikan kadar $\mathrm{CO}_{2}$ di atmosfir sehingga terjadilah fenomena global warming yang saat ini tidak bisa dihindari. IPCC (Intergovernmental Panel for Climate Change) pada tahun 2001 melaporkan peningkatan $\mathrm{CO}_{2}$ di atmosper sebesar 380 ppm dari sebelumnya 350 ppm yang diikuti oleh peningkatan suhu bumi, terlebih saat ini konsentrasi $\mathrm{CO}_{2}$ di atmosfer sudah melebihi 400 ppm (NOAA (National Oceanic and Atmospheric Administration). Dampak pemanasan global ini dapat mempengaruhi metabolisme tanaman dan menurunkan hasil panen. Perubahan iklim ini dapat mempengaruhi sebaran curah hujan menjadi 
tidak merata. Kondisi seperti ini dapat memperparah kondisi drainase lahan yang buruk sehingga menyebabkan genangan pada areal pertanian khususnya areal pertanaman tebu. Genangan ini merupakan gangguan alam yang mempengaruhi produksi tanaman dan produksi ternak di seluruh dunia. (Serres B J \& Voesenek, 2008; Colmer \& Vosenek, 2009). Kondisi genangan tersebut dapat menganggu sistem respirasi akar tanaman karena kandungan oksigen dalam tanah menjadi berkurang sehingga mempengaruhi pertumbuhan dan perkembangan tanaman.. Dengan kata lain tanaman dapat mengalami hipoksia yang akan mengalami keracunan (Blom \& Voesenek, 1996; Serres \& Voesenek, 2008). Munculnya stress lingkungan abiotik akan dibarengi dengan perubahan bentuk dan tampilan morphologi tanaman khususnya akar (Vartapetian and Jackson, 1997; Jackson and Colmer, 2005). Dalam kondisi genangan akar tanaman akan cenderung memanjang lebih cepat menuju daerah kaya akan oksigen (Nishiuchi et al., 2012) sehingga pertumbuhan akar akan terlihat lebih dominan dibanding pada kondisi normal. Salah satu mekanisme tanaman toleran terhadap stress abiotik adalah respons buka-tutup stomata atau konduktansi stomata $\left(\mathrm{g}_{\mathrm{s}}\right)$. Stomata berperan sebagai alat untuk lalu-lintas gas $\left(\mathrm{CO}_{2}\right.$ dan $\left.\mathrm{H}_{2} \mathrm{O}\right)$ dari luar ke dalam tanaman atau dengan kata lain proses metabolisme berjalan seiring dengan tingkat buka-tutup stomata. Bila metabolisme terhambat maka konduktansi stomata akan menurun bahkan terhenti sama sekali. Pada kondisi tergenang, seringkali konduktansi stomata tanaman menurun disebabkan oleh menurunnya nilai konduktansi akar (Davies and Flore 1986), konsekuensinya laju fotosintesis akan menurun (Dias-Filho 2002, Bertolde et al. 2012). Tanaman tomat dilaporkan mengalami penurunan tingkat konduktansi stomata dan transpirasi sebesar $30-40 \%$ dalam perlakukan genangan air selama 24 jam (Kent and Theodorore, 1982). Dengan demikian sifat konduktansi stomata sangat erat kaitannya dengan sifat tolerensi tanaman terhadap cekaman aibotik berupa genangan air. Tujuan penelitian ini adalah untuk mengevaluasi sifat konduktansi stomata beberapa genotipe tanaman tebu yang ditanam dalam genangan air untuk selanjutnya digunakan pada evaluasi sifat fisiologis tebu di masa mendatang.

\section{Bahan dan Metode}

Bahan tanaman yang dipakai pada penelitian ini adalah empat genotip tebu yaitu Kidang Kencana (KK), PSJT941 (V1), GMP1 (V2), dan GMP2 (V3). Penanaman tanaman tebu dilaksanakan dalam polybag berukuran $25 \mathrm{~cm} \times$ $50 \mathrm{~cm}$ dengan media tanam tanah Inceptisol. Tiap polybag berisi satu mata tunas tebu. Percobaan ini dilakukan di Kebun Percobaan Fakultas Pertanian Universitas Padjadjaran dengan ketinggian tempat sekitar $750 \mathrm{~m}$ dpl, tipe iklim C3 menurut klasifikasi Oldemann, pada bulan April sampai Oktober 2017. Masingmasing genotipe berjumlah empat tanaman yang diulang tiga kali sehingga populasi total adalah 48 tanaman. Penelitian ini menggunakan metode eksperimen dalam lingkungan tidak terkendali. Rancangan percobaan adalah Rancangan Acak Kelompok sederhana dengan satu faktor yaitu genotipe tebu. Pengamatan utama yang dilakukan adalah pengamatan konduktansi stomata $\left(\mathrm{g}_{\mathrm{s}}\right)$ menggunakan alat leaf porometer (Decagon inc. US), dan pengamatan suhu kanopi tanaman tebu menggunakan alat therlam imaging camera (Flir System inc.). Sedangkan pengamatan penunjang adalah berat kering akar tanaman, serta rata-rata suhu harian.

\section{Hasil dan Pembahasan}

Hasil pengamatan nilai $g_{s}$ pada perlakuan tanpa genangan (0 HSP (Hari Setelah perlakuan)) dari keempat genotipe tebu berkisar antara 952.7 mmol $\mathrm{H}_{2} \mathrm{O} \cdot \mathrm{m}^{-2} \mathrm{~s}^{-1}$ untuk KK sampai $561.4 \mathrm{mmol}$ $\mathrm{H}_{2} \mathrm{O} \mathrm{m}^{-2} \cdot \mathrm{s}^{-1}$ untuk V3 (Gambar 1). Pada 7 HSP genangan air, nilai $g_{s}$ keempat genotipe mengalami penurunan yaitu berkisar antara $511 \mathrm{mmol}$ $\mathrm{H}_{2} \mathrm{O} \cdot \mathrm{m}^{-2} \cdot \mathrm{s}^{-1}$ untuk V3 sampai $240 \mathrm{mmol} \mathrm{H}_{2} \mathrm{O} \cdot \mathrm{m}^{-}$ $2 \mathrm{~s}^{-1}$ untuk KK (Gambar 1). Dilihat dari tingkat penurunan nilai $\mathrm{g}_{\mathrm{s}}$ genotipe $\mathrm{KK}$ memiliki tingkat penurunan nilai $g_{s}$ pada 7 HSP paling tinggi yaitu sebesar $62 \%$, sedangkan getotipe V3 memiliki tingkat penurunan $\mathrm{g}_{s}$ paling kecil sebesar 9\%. Nilai gs ini sebagian linear dengan nilai temperatur kanopi tanaman tebu dimana suhu kanopi $\left(\mathrm{s}_{\mathrm{k}}\right)$ genotipe KK lebih tinggi dari genotipipe V3 dan V2, sedangkan terhadap genotipe V1 sebaliknya (Gambar 2). Begitu pula nilai berat kering akar (bk), genotipe KK memiliki 
nilai bk sebesar $153 \mathrm{~g}$ lebih kecil dibanding genotipe V3 sebesar $210 \mathrm{~g}$ Secara umum keempat genotip tebu menunjukkan penurunan nilai $\mathrm{g}_{\mathrm{s}}$ pada $7 \mathrm{HSP}$ dan $\mathrm{s}_{\mathrm{k}}$ pada $71 \mathrm{HSP}$ dengan perlakukan genangan dibanding tanpa perlakuan genangan (0 HSP). Sebaliknya nilai berat kering akar mengalami peningkatkan pada 85 HSP dibanding tanpa perlakuan (Gambar 3.).

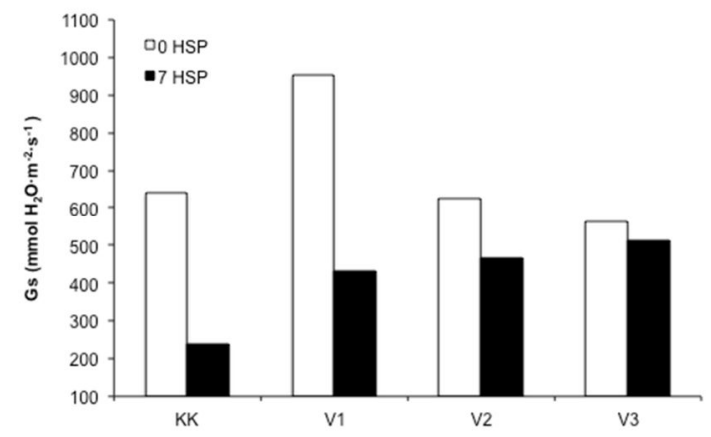

Gambar 1. Konduktansi stomata empat genotipe tebu: KK, V1, V2, dan V3 pada perlakuan tanpa genangan (0 HSP (bar putih)) dan genangan (bar hitam) pada 7 HSP.

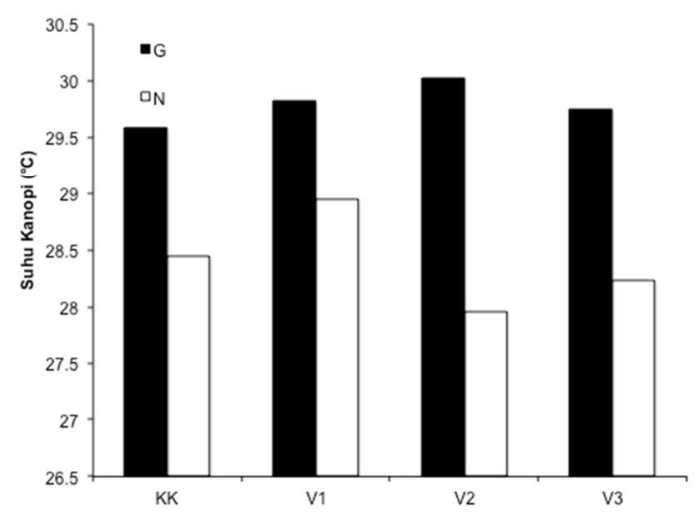

Gambar 2. Suhu Kanopi empat genotipe tebu: KK, V1, V2, dan V3 pada perlakuan tanpa genangan $(\mathrm{N})$ dan genangan $(\mathrm{G})$ pada $71 \mathrm{HSP}$.

Respons gs tiap genotipe tebu menunjukkan respons yang jelas bahwa perilaku stomata dalam kondisi cekaman abiotik seperti genangan air menjadi sangat penting. Penurunan nilai $g_{s}$ menandakan tanaman mengalami cekaman yang akan mempengaruhi tingkat metabolime. Akibatnya, secara langsung mempengaruhi penurunan laju fotosintesis karena $\mathrm{g}_{\mathrm{s}}$ merupakan gerbang awal masuknya $\mathrm{CO}_{2}$ sebagai bahan dasar fotosintesis (Dias-Filho 2002, Bertolde et al. 2012). Penurunan nilai $g_{s}$ juga berkorelasi positif terhadap suhu kanopi tanaman dimana suhu kanopi akan meningkat bila aktivitas stomata menurun. Genotype KK memiliki nilai gs terkecil dibanding genotype lainnya disebabkan KK merupakan genotype lokal yang beradaptasi dan berkembang di dusun Kidangkencana, Jawa Barat bukan hasil pemuliaan (P3GI dalam litbang.pertanian.go.id). Genotipe tebu lainnya merupakan hasil perbaikan sifat-sifat melalui proses pemuliaan. Sebagai contoh genotipe V3 merupakan genotipe yang didesign tahan genangan cocok untuk ditanam di lahan sawah dalam sistem reynoso. Sedangkan genotype V1 adalah genotype anjuran pada lahan tegalan (P3GI). Dengan demikian perilaku konduktansi stomata dapat dijadikan parameter tingkat toleransi cekaman air. Selain itu, salah satu mekanisme tanaman tercekam genangan air adalah tanaman akan memproduksi akar serabut lebih banyak untuk mencapai permukaan air dalam mengambil oksigen (Nishiuchi et al., 2012). Hasil analisis berat kering akar menunjukkan pertumbuhan akar genotipe tebu dalam cekaman air lebih banyak dibanding pertumbuhan akar dalam kondisi tanpa cekaman air (Gambar 3). Genotipe V3 memiliki berat akar paling besar diantara genotipe lainnya menandakan tingkat toleransi lebih baik serta selaras dengan respons konduktansi stomata.

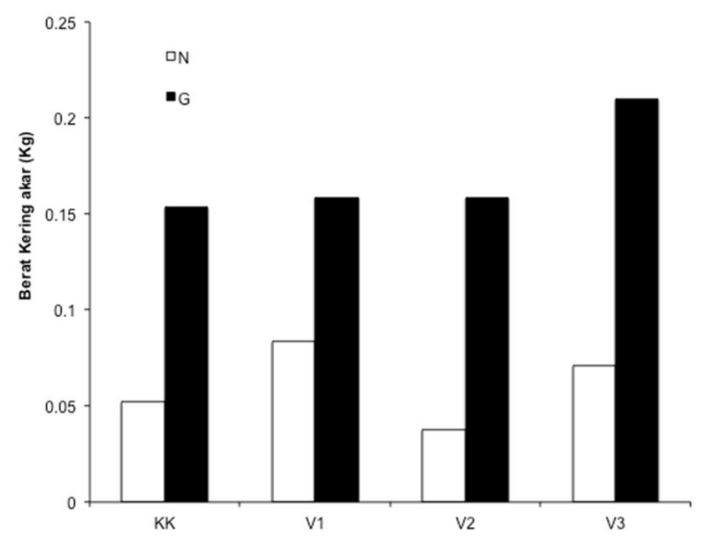

Gambar 3. Berat kering akar empat genotipe tebu: KK, V1, V2, dan V3 pada perlakuan tanpa genangan $(\mathrm{N})$ dan genangan $(\mathrm{G})$ pada 85 HSP.

\section{Kesimpulan dan Saran}

Terdapat diversitas respons konduktansi stomata stomata diantara beberapa varietas tebu yang berkorelasi positif dengan suhu kanopi tanaman. Salah satu mekanisme mempertahankan diri dalam kondisi genangan adalah dengan memperbanyak pertumbuhan akar serabut. Penelitian lanjutan perlu dilakukan 
untuk menguju faktor fisiologis dan morfologis lainnya untuk lebih memperdalam infromasi respons beberapa genotipe tebu tersebut.

\section{Daftar Pustaka}

Bertolde, F.Z., Almeida, A.-A.F., Pirovani, C.P. et al.: Physiological and biochemical responses of Theobrama cacao L. genotypes to flooding. Photosynthetica 50: 447-457, 2012.

Blom CWPM, Voesenek LACJ (1996) Flooding: the survival strategies of plants. Trends in Ecology \& Evolution 11, 290-295. doi: 10.1016/0169-5347(96)10034-3

Colmer, T.D. and Voesenek, L.A.C.J. 2009. Flooding tolerance: suites plant traits in variable environments. Functional Plant Biology 36: 665-681.

Davies, F.S., Flore, J.A. 1986. Flooding, gas exchange and hydraulic conductivity of highbush blueberry. Physiol. Plantarum 67: 545-551,

Dias-Filho, M.B.: Tolerance to flooding in five Brachiaria brizantha accessions. Pesqui. Agropecu. Bras. 37: 439-447, 2002.

Folzer H, Dat J, Capelli N, Rieffel D, Badot P-M (2006) Response to flooding of sessile oak: An integrative study. Tree Physiology 26,
759-766

IPCC (2001). Climate change 2001: Synthesis report. Summary for policy makers. Website: http://www.ipcc.ch

IPCC (2007). Climate change 2007: The physical science basis. Summary for policy makers. Website: http://www.ipcc.ch

Jackson MB, Colmer TD (2005) Response and adaptation by plants to flooding stress. Annals of Botany 96, 501-505

Kent J Bradford and Theodore C. Hsiao Stomatal Behavior and Water Relation of Waterloggeg Tomato Plants Plant Physiology 1982 (70): 1508-1513

Nishiuchi, S.,Yamauchi, T., Takahashi, H., Kotula, L., Nakazono, M., 2012. Mechanisms for coping with submergence and waterlogging in rice. Rice 5, 2.

NOAA, 2017. Diakses melaui https://www.esrl. noaa.gov/gmd/ccgg/trends/

P3GI, 2008. Deskripsi Tebu Varietas Kidang Kencana (Nama Asal PA198). Diakses melaui perkebunan.litbang.pertanian.go.id

Serres-Bailey J, Voesenek LACJ (2008) Flooding stress: acclimations and genetic diversity. Annual Review of Plant Biology 59, 313-339.

Vartapetian BB, Jackson M (1997) Plant adaptations to anaerobic stress. Annals of Botany 79, 3-20 